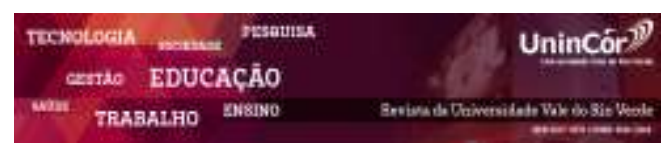

Revista da Universidade Vale do Rio Verde ISSN: 1517-0276 / EISSN: 2236-5362 Vol. 16 | n. 2 | Ano 2018

Marcelo da Silva Mantovani Universidade Vale do Rio Verde marcelo.mantovani89@hotmail.com

Maria Celina da piedade Ribeiro Universidade Vale do Rio Verde maria.ribeiro@unincor.edu.br

\section{A INFLUÊNCIA DA COMUNICAÇÃO NÃO VERBAL NA INTERAÇÃO HUMANA}

\section{RESUMO}

A comunicação é um dos principais meios de interação na qual se compartilha ideias, mensagens, sentimentos e é uma ferramenta importantíssima de trabalho. No entanto, a comunicação não está restrita somente na verbal, mas na não verbal, ou seja, uma série de gestos, de expressões faciais e corporais que completam a conversação e a torna mais eficaz. O corpo tem sido alvo de estudos em diversos campos do conhecimento, que consiste pela variedade de abordagens acerca do assunto. Nosso corpo está a todo instante emitindo informações, que na maioria das vezes passam despercebidos pelos interlocutores. Isso porque o uso das palavras fez com que a atenção fosse focada na linguagem verbal, passando por despercebido o que o corpo diz. Essa leitura da linguagem corporal traz informações riquíssimas de como o indivíduo interage frente aos estímulos oriundos do meio em que se encontra, levando-se em conta que os estímulos partem da situação vivenciada pelas pessoas que estão em interação e que cada sujeito os interpreta de maneira única. Partindo do pressuposto que através da comunicação o homem se relaciona e transmite seus conhecimentos para o mundo, este presente estudo enfatiza a influência da comunicação não verbal para o autoconhecimento e conhecimento do outro. Ainda que com o aparecimento da fala, a linguagem corporal nunca desaparece completamente, mesmo que inconscientemente, o corpo fala. O presente estudo tem caráter descritivo, constituído de pesquisa bibliografia através de artigos, teses, livros nacionais e internacionais que abordam o tema em seus respectivos ângulos.

Palavra-chave: Comunicação não verbal. Comunicação

\section{THE COMMUNICATION INFLUENCE} NO VERBAL IN HUMAN INTERACTION

\begin{abstract}
Communication is one of the main means of interaction in which ideas, messages, feelings are shared and is a very important tool of work. However, communication is not restricted only in the verbal, but in the non-verbal, that is, a series of gestures, facial and body expressions that complete the conversation and make it more effective. The body has been the subject of studies in several fields of knowledge, which consists of the variety of approaches on the subject. Our body is constantly sending out information, which most of the time passes unperceived by the interlocutors. This is because the use of words has made the attention focused on verbal language, going unnoticed by what the body says. This reading of body language brings rich information about how the
\end{abstract}


individual interacts with the stimuli coming from the environment in which they are, taking into account that the stimuli depart from the situation experienced by the people who are in interaction and that each subject interprets them in a way unique. Based on the assumption that through communication man relates and transmits his knowledge to the world, this present study emphasizes the influence of nonverbal communication for self-knowledge and knowledge of the other. Although with the appearance of speech, body language never completely disappears, even if unconsciously, the body speaks. The present study has a descriptive character, consisting of research bibliography through articles, theses, national and international books that approach the theme in their respective angles.

Keywords: Nonverbal communication. Communication.

Recebido em: 13/02/2018 - Aprovado em: 31/08/2018 - Disponibilizado em: 15/12/2018

\section{INTRODUÇÃO}

Instintivamente, o corpo fala! A linguagem corporal passa por despercebido por muitos. Mas é tão importante quanto a comunicação verbal, expressa por palavras e a vocal determinada pela entonação, o tom e timbre de voz. Melhor dizendo, a linguagem corporal e vocal apoia-se uma na outra para expressar o estado emocional e físico de uma pessoa em determinada situação (RAMOS \& BOTAGARAI, 2012).

O corpo nada mais é do que o maior meio de comunicação que temos. Através dele podemos expressar inúmeras informações: através do choro, para expressar aborrecimento; o sorriso, para manifestar alegria; o beijo e o abraço, para transmitir afeto; as doenças, que sinalizam que algum fator externo atingiu nosso interno. (WEIL \& TOMPAKOW, 2012).
No cotidiano, a comunicação humana se faz principalmente pela palavra falada, acompanhada de posturas para expressar atitudes e sentimentos em relação àqueles que o cercam. Por isso, é necessário estar atento para decodificar as mensagens não verbais que nos é transmitida. Pois quando isso não acontece estima-se que há uma perda de $65 \%$ do que é comunicado. Mas se no momento em que a pessoa domina as mensagens não verbais, ele passa a conduzir melhor o processo de comunicação de forma eficaz e consegue atingir os objetivos propostos. Afinal, "Conhecer o interior do homem pelo seu exterior é uma arte" (MARTINEZ, 2009).

Mas antes de tudo, é necessário o autoconhecimento. Essa tarefa não é mais fácil nem mais simples do que conhecer outra pessoa. Acredite, é mais fácil o homem ir à lua, mapear o DNA, criar uma grande rede de computadores do que acessar o interior de 
um indivíduo. Mas a partir do momento em que temos a liberdade de enquadrarmos em diversos padrões que nos possibilitam aprimorarmos nosso autoconhecimento, nossas qualidades, apararmos nossos defeitos, tornando-nos cidadãos melhores, mais eficazes e felizes. Por conseguinte, será possível respeitar e aceitar melhor o outro, visto que sabemos que o outro é o que é, porque seus padrões assim determinam (CALLEGARI, 2015).

Partindo do pressuposto que através da comunicação o homem se relaciona e transmite seus conhecimentos para o mundo, este presente estudo enfatiza a influência da comunicação não verbal para o autoconhecimento e conhecimento do outro. Trata-se de um estudo descritivo, constituído de pesquisa bibliografia através de artigos, teses, livros nacionais e internacionais que abordam o tema em seus respectivos ângulos.

\section{MATERIAIS E MÉTODOS}

Trata-se de um estudo descritivo, a partir de um levantamento bibliográfico sobre os seguintes descritores: comunicação não verbal, cinésica, proxê a partir de um levantamento bibliográfico sobre os seguintes descritores: comunicação não verbal, cinésica, proxêmica partir de um levantamento bibliográfico sobre os seguintes descritores: comunicação não verbal, cinésica, proxêmica partir de um levantamento bibliográfico sobre os seguintes descritores: comunicação não vebal, cinésica, proxêmica, tacêsica, paralinguagem.

Foram selecionados artigos e livros nacionais e internacionais que focam a importância, a função e as implicações da Comunicação Não Verbal na interação humana. O critério de seleção obedeceu à demanda pela abordagem da temática, que em grande parte foram realizadas no atendimento em saúde.

O resultado destas buscas aproveitouse também de teses e artigos citados em suas referências bibliográficas.

\section{REVISÃO DE LITERATURA}

\section{Comunicação não verbal}

O corpo é construído socialmente nas interações do indivíduo com o meio e está a todo o momento em transformação. $\mathrm{O}$ corpo pode ser comparado como um mar de imagens que exprimem através da linguagem gestual e visual, que são elaboradas e reelaboradas no universo da cultura. Essa cultura, por sua vez, que caracteriza uma sociedade, cria um "mundo de significações" manifestadas pelo corpo. Seria como uma identidade própria de determinados grupos, profissões e instituições, que podem estar associadas a várias heranças culturais. Entretanto, a comunicação não verbal, concretizada por meio de expressões corporais, de maneira consciente ou não, resultando em formas diversas e 
diferentes de se comunicar (NOGUEIRA \& FARIA, 2013).

Para Gois et. al (2011) a comunicação não verbal assume papel importante na eficaz relação entre as pessoas. O corpo fala, expõe "verdades", reforça ideias, favorece ou dificulta o entendimento; enfim, dá ênfase à comunicação. E, para entender o relacionamento entre as pessoas, deve-se analisar o que a linguagem corporal está dizendo, considerando-se que cada indivíduo é um ser único diante de situações novas que se apresentam. Isso, de certa forma, ficou um pouco esquecido, porque o uso das palavras fez com que a atenção fosse focada na linguagem verbal, passando por despercebido o que o corpo diz.

Essa leitura da linguagem corporal traz informações riquíssimas de como o indivíduo interage frente aos estímulos oriundos do meio em que se encontra, levando-se em conta que os estímulos partem da situação vivenciada pelas pessoas que estão em interação e que cada sujeito os interpreta de maneira única. "Quem tem olhos para ver e ouvidos para ouvir, pode convencer-se de que nenhum mortal pode guardar um segredo. Se seus hábitos permanecem silenciosos ele conversa com a ponta dos dedos; a revelação transpira dele por todos os poros (FREUD, 1996, p. 72)". O silêncio fala mais que mil palavras e o corpo é um instrumento capaz de revelar essas mensagens de sentimentos ocultos, verbalizado ou não.

\section{Linguagem - Meio de comunicação}

Dando ênfase ao estudo, é sabido que a comunicação se faz através da linguagem, que viabiliza a transmissão e a recepção de mensagens. Este termo circula por livros, artigos científicos há muito tempo. Desde a antiguidade, grandes filósofos dentre eles Platão e Aristóteles realizaram os primeiros ensaios do que seria a linguagem. A partir de então, esse assunto se desenvolveu até atingir a condição de temas de grande relevância em vários saberes científicos (FERREIRA, 2012).

Logo, muitas tentativas e definições sobre o que seria a linguagem foram produzidas. Analisando algumas dessas definições no Dicionário Contemporâneo da Língua Portuguesa (1881) define que: é a expressão do pensamento por meio de palavras, sistema de sinais empregados pelos homens para exprimir e transmitir ideias e pensamento, conjunto de sinais produzidos e interpretados instrutivamente por todos os homens, como, os a fala, os gestos, as atitudes, os gritos olhares, etc.

Nos dicionários modernos da língua portuguesa, como Aurélio (1983), traz a definição de linguagem sendo: o uso da voz e outros sons que articulam formando palavras, as quais podem se articular em frases maiores, para fins de expressão e comunicação entre as pessoas, sendo também a forma de expressão oral ou escrita própria de um indivíduo, grupo ou classe. 
Através dessa comparação é possível perceber que mesmo após um século, as duas definições possuem muitos elementos em comum. Principalmente a ideia de que a linguagem se relaciona à fala, sons, palavras para exprimir ideias e sentimentos na comunicação e interação entre os humanos. Com exceção da primeira definição, observa-se a exclusão da expressão corporal sendo uma forma de linguagem. Portanto, no que se concerne ao termo da linguagem, conclui-se que é relativamente fácil definir, no entanto, difícil de conceituar (FERREIRA, 2012).

\section{Os quatro campos de estudo na comunica-} ção não verbal (CNV)

Vários cientistas dedicaram suas vidas em estudos sobre o tema. Dentre eles Charles Darwin, que corroborou com grandes estudos e descobertas sobre a evolução dos seres vivos. A Expressão das Emoções no Homem e nos Animais (1872), escrito pelo britânico naturalista trata sobre como o ser humano e os animais expressam as suas emoções. Esse livro é um marco na história da comunicação não verbal, pois foi a primeira obra, com viés científico, de grande circulação sobre as emoções e as expressões faciais (SENNA, 2017).

Nessa época, havia uma polêmica sobre a natureza "divina" do ser humano, mesmo na fisiologia. Contudo a investigação de Darwin à expressão das emoções deu íncio ao ler uma obra do anatomista Charles
Bell. De acordo com este autor, defendia a existência de músculos únicos e divinamente criados para as expressões humanas. Como para Darwin esta visão que se opunha à hipotese de que a origem do homem é partilhada entre animais, resolveu analizá-la. A importância desses estudos consistiu na elaboração da hipótese de que certas emoções podem ser consideradas universais, compartilhadas por todos os seres humanos (CASTILHO e MARTINS, 2012).

Contudo a $\mathrm{CNV}$ não ficou restrita somente à expressões faciais. Pesquisadores estudaram o comportamento humana em relação ao espaço.

\section{Comunicação Proxêmica - O uso do espa-} ço

Apesar de ser pouco divulgada, a comunicação proxêmica foi denominada pelo antropólogo Edward Twitchell Hall no ano de 1963, que a definiu como "o estudo de vários tipos de sinais e traços distintivos relativos ao uso do espaço nas relações humanas." Ou melhor, a proxêmica descreve a distância entre as pessoas, conforme a sua interação, podendo variar de acordo com a situação social, gênero e preferências individuais (TERRA \& VAGHETTI, 2014).

Assim, este mesmo autor, considerou quatro distâncias adotadas nas relações: a) Distância intima (0-50) ocorre contato físico através de pequenos movimentos; a visão, o cheiro e o calor do corpo são perceptíveis; b) 
Distância pessoal $(50-120 \mathrm{~cm})$, não há contato corporal; o calor e o odor do outro não são perceptíveis; c) Distância social (120$360 \mathrm{~cm})$, Não há contato físico e o tom de voz é normal; d) Distância pública (acima de 360) refere-se aquela mantida nas conferências e comícios, a voz pode ser alta e o contato visual opcional (HALL, 1986).

Neste sentido, Hall menciona alguns fatores da teoria proxêmica: postura-sexo, que analisa o sexo dos participantes e a posição básica dos interlocutores (de pé, sentado, deitado); eixo sociofugo-sociopeto, que analisa o ângulo dos ombros com relação à outra pessoa, a posição dos interlocutores pode ser face a face, de costas um para o outro, ou qualquer outra angulação. Sendo que sociofugo demonstra desencorajamentos da interação e o sociopeto demonstra o inverso. Fatores cinésicos ou cinestésicos, que analisa o contato físico a curta distância, como o toque ou o roçar da pele, e o posicionamento das partes do corpo; comportamento de contato, este fator analisa as formas de relações táteis como acariciar, agarrar, apalpar, segurar demoradamente, apertar, toque localizado, roçar acidental, ou nenhum contato físico; contato visual verifica o modo de contato, como p. ex. olho no olho, ou ausência de contato; código térmico detém-se calor percebido pelos interlocutores; código olfativo analisa as características e o grau de odor sentido pelos mediadores; Volume da voz analisa a percepção dos interlocutores com relação ao vo- lume e intensidade da fala utilizada pelos interlocutores (GALVÃO et. al, 2006).

\section{Comunicação Cinésica - O movimento nesse espaço}

A pesquisa no campo da $\mathrm{CNV}$ intensificou-se a partir dos anos 60 e Ray Birdwhistell ao se dedicar aos estudos da linguagem do corpo, constatou que em uma conversa que estabelecemos cara a cara com outra pessoa, o componente verbal utilizado é menor do que $35 \%$ e o não-verbal (posturas, gestos, expressões faciais) é superior a $65 \%$. Percebe-se através desta analise a importância de decodificar as mensagens que o corpo emite na finalidade de aprimorar a comunicação (SCHIMIDT \& SILVA, 2014).

O antropólogo Birdwhistell ressalta ainda, que não há gestos ou movimentos corporais que possam ser considerados como símbolos universais e, que toda cultura tem seu repertório gestual. Partindo deste pressuposto ele estabeleceu alguns critérios para facilitar a compreensão da cinésica: a) o contexto fornece o significado ao movimento ou expressão corporal; b) a cultura padroniza a postura corporal, o movimento e expressão facial; c) o comportamento dos membros de um grupo é influenciado pelas suas próprias atividades corporais e fonéticas; d) os comportamentos têm significados culturalmente reconhecidos e validados (SILVA, 2000).

Estudar a expressão facial da emoção é um fascínio, segundo Paul Ekman “as emo- 
ções nunca nos contam a sua fonte. Quando você entrevista alguém que tem medo de ser suspeito de um crime, você não sabe se o medo é de ser pego ou de ser incrédulo. $\mathrm{Pa}$ rece exatamente o mesmo. Você pode dizer pela expressão facial qual é a emoção, mas não a causa." Mesmo nossos sentimentos sendo revelados pelos gestos e posturas corporais, ainda sim temos o direito de manter o sigilo das infinitas causas. É preciso ser cauteloso ao estudar essas expressões faciais, somos limitados a definir apenas as emoções, a causa ainda continua sendo um mistério (MAGALHÃES, 2016).

\section{Comunicação Tacésica - A importância do} toque

Outro meio de comunicação não verbal é o toque ou tacésica. O ato de tocar é considerado uma das maneiras mais importante na proximidade física para demonstrar afeto, envolvimento, segurança e a valorização do ser humano. Além disso, na área da saúde é um dos instrumentos primários que os profissionais dispõem para estabelecer contato direto com os pacientes. Estudos demonstram inúmeros efeitos benéficos que aumentam a resistência do organismo contra as doenças, devido a liberação de endorfinas, responsáveis pela sensação de bem estar (PINHEIRO et al, 1998).

Para Cirqueira (2012) tacésica é o estudo do toque e as características que o envolvem como: pressão exercida, local do to- que, idade e sexo dos interlocutores, entre outros. Acrescenta que o ato físico em sí, não é um acontecimento emocional, mas seus níveis sensoriais provocam alterações neurais, granulares, musculares e mentais, as quais denominados emoções. Por isso, muitas vezes o tato não é "sentido" como uma sensação e sim, efetivamente como emoção. A começar pelo tipo de receptor: a pele, que depende, em grande parte, do tipo de estimulação ambiental recebida.

No entanto, é preciso estar atento quanto às influências culturais que determinará a comunicação e a interação a partir do toque. Há diversas formas de expressas pelas diferentes culturas. Para os orientais, "tocar, ainda que com os olhos é um ato sagrado, o encontro dos olhos, é o encontro das almas". Entretanto, deve-se ficar atento às diferenças culturais e individuais. Uma pessoa com atitude introspectiva pode indicar certa restrição ao toque, considerando que existem diversos fatores que possibilitam maior ou menor aceitação ao toque (MONTAGU, 1988).

\section{Paralinguagem - Uso da voz para expres- sar sentimentos}

Por fim, não menos importante, a paralinguagem. Segundo Cruz (2010) ela estuda os sons produzidos pelo aparelho fonador. É utilizada para modificar as características sonoras do que está sendo falado, no intuito de fornecer as emoções do emissor. A paraliguagem pode ser expressa conscientemente 
ou inconscientemente, incluindo o tom de voz, volume, velocidade da fala, até mesmo, uma expressão facial.

Os elementos citados contribuem para qualificar a interação com as pessoas e compreender o papel do corpo na expressão emocional. Mas também tem sido importante no avanço de sistemas de tecnologias para aperfeiçoar jogos, robôs, as interfaces touchscreen, tornando as expressões faciais nestes sistemas cada vez mais semelhantes a dos humanos. Para esse objetivo, têm sido desenvolvidos vários sistemas de codificação que pode interpretar ou criar expressões corporais, com base em posturas estáticas, dados de captura de movimento ou vídeos. No entanto, nenhum sistema foi baseado no Envolvimento Muscular e Eletromiografia - EMG, que permitiria a investigação sobre respostas automáticas sem movimento ostensivo e construir expressões emocionais naturais com base em dados de movimento biologicamente válido (HUIS IN 'T VELD et al, 2014).

É certo afirmar que a tecnologia tem influenciado e felicitado cada vez mais na comunicação através das mensagens; no entanto, o contato pessoal tem ficado em segundo plano. Internet, intranet, portais corporativos são instrumentos importantes na comunicação entre as pessoas, mas não suprem a necessidade de encontros presenciais. Ao contrário, ampliam essa necessidade (WOLTON, 2010).

\section{CONSIDERAÇÕES FINAIS}

O corpo tem sido alvo de estudos em diversos campos do conhecimento, que consiste pela variedade de abordagens acerca do assunto. A intenção não é debater minuciosamente sobre o tema. Mas salientar a importância do corpo como instrumento para a decodificação de mensagens não verbal que nos é transmitida.

Conclui-se que as expressões gestuais e visuais manifestadas pelo corpo é modelada e influenciada pela cultura. Independente de qual seja a sociedade é determinado significações para definir tais expressões que dizem respeito à afetividade humana, imprimindo sentimentos, emoções, qualidades e um contexto que permite ao indivíduo não somente perceber e compreender o que significam as palavras, mas compreender o que está sendo emitido ao interlocutor.

É importante ressaltar que o atual estudo, não relata respostas e nem conclusões fechadas, mas uma abertura a futuras propostas de pesquisa sobre o tema abordado.

Contudo, pode-se afirmar que desde o nascimento, o ser humano necessita do seu corpo para se comunicar, ainda que com o aparecimento da fala, a linguagem corporal nunca desaparece completamente, mesmo que inconscientemente, o corpo fala. 


\section{REFERÊNCIAS}

AULETE, Francisco Júlio de Caldas. Parceria: PEREIRA, António Maria. Diccionario Contemporaneo da Lingua Portugueza - Lisboa, 1881.

CASTILHO, Fernando Moreno e MARTINS, Lilian Al Chueyr Pereira. As concepções evolutivas de Darwin sobre a expressão das emoções no homem e nos animais. Revista da Biologia, 9(2): 12-15. 2012. Disponível em: <https://ibralc.com.br/linha-tempolinguagem-corporal/> Acesso 05 de dezembro de 2017.

CALLEGARI, Samantha. O corpo fala, você sente. 2015. Disponível em: $<$ http://universomistico.com.br/o-corpo-fala-vocesente> Acesso dia 29 de agosto de 2017.

CIRQUEIRA, Flávia Dantas. A comunicação verbal e não verbal de idosos nas práticas fisioterapêutica. 2012. Disponível em:

<http://dspace.bc.uepb.edu.br/jspui/bitstream/1234567 89/861/1/PDF\%20-

\%20Fl\%C3\%A1via\%20Dantas\%20Cirqueira.pdf>

Acesso dia 29 de agosto de 2017.

CRUZ, Wilton Ribeiro. Paralinguagem. 2010. Disponível em:

<http://www.webartigos.com/artigos/paralinguagem/4 6095/> Acesso dia 29 de fevereiro de 2016.

FERREIRA, Aurélio Buarque de Hollanda. Pequeno Dicionário Brasileiro da Língua Portuguesa. 1 ed. Gama, 1983.

FERREIRA, Rafael Pinheiral. Linguagens corporais: psicomotricidade e afetividade em crianças de 0 a 2 anos. 2012. Disponível em:

<http://www.avm.edu.br/docpdf/monografias_publica das/T207404.pdf> Acesso dia 29 de agosto de 2017.

FREUD, Sigmund. Histeria (1888). In: ___ . Publicações pré-psicanalíticas e esboços inéditos. Rio de Janeiro: Editora Imago, 1996. p. 77-96;

Marli Teresinha Gimeniz Galvão1 et. al. Análise da comunicação proxêmica com portadores de HIV/AIDS. Rev. Latino-am Enfermagem. 2006. Disponível em:

<http://www.revistas.usp.br/rlae/article/view/2322/246 9> Acesso dia 29 de agosto de 2017.

GOIS, Aline Kátia de. A linguagem do corpo e a comunicação nas organizações. Revista Anagrama: Ver. Científica Interdisciplinar da Graduação. Ano 4. Edição 4. 2011. Disponível em:

<http://www.revistas.univerciencia.org/index.php/anag rama/article/viewFile/7608/7004> Acesso dia 29 de agosto de 2017.
HALL. E. T. A dimensão oculta. Lisboa: Relógio d'Água, 1986.

HUIS IN 'T VELD, Elisabeth M. J.; Geert J. M. van Boxtel; Beatrice de Gelder. "The Body Action Coding System II: Muscle Activations during the Perception and Expression of Emotion." Frontiers in Behavioral Neuroscience 8 (2014): 330. PMC. Disponível em: <http://www.ncbi.nlm.nih.gov/pmc/articles/PMC4172 051/> Acesso dia 29 de agosto de 2017.

MAGALHÃES, A. Freitas. Manual de codificação cientifica da face humana. Editora Leya, 2016.

MARTINEZ, Valquiria. Os mistérios do rosto. Editora Madras. Ed. 02, 2009.

MONTAGU, Ashley. Tocar: o significado da pele. São Paulo: SUMUS, 1988.

NOGUEIRA, Maria Francisca Magalhães; FARIA, Cláudia Souza Oriente de. A comunicação não verbal nas organizações: o corpo fala. Rev. de Comunicação e Epistemilogia da Universidade Católica de Brasília. 2013. Disponível em:

<http://portalrevistas.ucb.br/index.php/RCEUCB/artic le/viewFile/5230/3302> Acesso dia 29 de agosto de 2017.

PINHEIRO, Eliana Moreira et al. Identificação dos tipos de toque ocorridos no atendimento de enfermagem de um serviço ambulatorial. Rev. Esc. Enf. USP., v.32, n.3, p. 192-98, out. 1998. Disponível em:<http://www.ee.usp.br/reeusp/upload/pdf/434.pdf> Acesso dia 29 de agosto de 2017.

RAMOS, Ana Paula; BORTAGARAI, Francine Manara. Comunicação não verbal na área da saúde Rev. CEFAC. 2012 Jan-Fev; 14(1):164-170. Disponível em: <http://www.scielo.br/pdf/rcefac/v14n1/186_10.pdf> Acesso dia 29 de agosto de 2017.

SENNA, Sérgio. Linha do tempo: linguagem corporal. Instituto Brasileiro de Linguagem Corporal (IBLC). Disponível em: <https://ibralc.com.br/linha-tempolinguagem-corporal/> 2012. Acesso 05 de dezembro de 2017.

SCHIMIDT, Teresa Cristina Gioia; SILVA, Maria Júlia Paes. Proxêmica e cinésica como recursos comunicacionais entre o profissionaç de saúde e o idoso. Rev. enferm. UERJ, Rio de Janeiro, 2012 jul/set; 20(3):349-54. Disponível em: <http://www.facenf.uerj.br/v20n3/v20n3a12.pdf> Acesso dia 29 de agosto de 2017.

SILVA, Lúcia Marta Giunta da et. all. Comunicação não verbal: reflexões da linguagem corporal. Rev. latino-am. Enfermagem. Ribeirão Preto, v. 8, n. 4, p. 
52-58, 2000. Disponível em:

<http://www.scielo.br/pdf/rlae/v8n4/12384> Acesso dia 29 de agosto de 2017.

TERRA, Alessandra Chaves; VAGHETTI, Helena Heidtmann. A comunicação proxêmica no trabalho da enfermagem: uma revisão integrativa de literatura.

Rev. Ciencia y enfermeria XX (1): 23-34, 2014, ISSN 0717-2079. Disponível em:

<http://www.scielo.cl/pdf/cienf/v20n1/art_03.pdf> Acesso dia 29 de agosto de 2017.

WEIL, Pierre; TOMPAKOW, Roland. Editora: Vozes. Ed. 68, 2012.

WOLTON, Dominique. Informar não é comunicar. Porto alegre. Sulina: 2010.

\section{Marcelo da Silva Mantovani}

Enfermeiro, Preceptor de estágios do Curso de Enfermagem da Universidade Vale do Rio Verde UninCor.

\section{Maria Celina da Piedade Ribeiro}

Enfermeira, Prof ${ }^{a}$. Mestre do Curso de Enfermagem da Universidade Vale do Rio Verde - UninCor. 